\title{
Alkalinity of Concrete Washout Water: A Pilot to Determine Jobsite Conditions for Potential Neutralization
}

\author{
Philip Street ${ }^{\mathrm{a}}$, Paul W. Holley, Ph.D. ${ }^{\text {a* }}$ \\ Auburn University, Auburn, AL 36830, U.S.A.
}

\begin{abstract}
The threat of stormwater contamination by concrete washout water from mixers, pumps, and other equipment has been identified through U.S. environmental policy for some time, primarily through the NPDES Permit Program. That said, enforcement of regulations prohibiting construction site release and spillage of this water has been sparse, at best. Recently, several urban areas and municipalities have begun levying fines upon general contractors for not taking proper measures to contain the washout water, and/or to properly dispose of it off of the construction site. This is prompting contractors, manufacturers, researchers, and other stakeholders to take notice, and to seek ways to mitigate the problem. This research continued the work of a recent project in which new containment product prototypes were developed, as part of a successful collaboration between construction management faculty and students, and their counterparts in industrial design. As the next phase of the study, this paper enumerates the findings of chemical analyses of washout water to develop a baseline level of contaminants. Primary contaminants measured include $\mathrm{pH} /$ alkalinity, total suspended solids, chlorides, oil and grease, and others. The authors' hope is that these findings will present a future opportunity to leverage textile, absorbents, and/or flocculants such as naturally occurring tree cellulose as potential neutralization strategies.
\end{abstract}

(C) 2019 The Authors. Published by Budapest University of Technology and Economics \& Diamond Congress Ltd. Peer-review under responsibility of the scientific committee of the Creative Construction Conference 2019.

Keywords: washout; environmental, concrete; alkalinity; containment

\section{Introduction and Review of Literature}

\subsection{Regulations}

The United States Clean Water Act (CWA) of 1972 established a basic structure for regulating the discharge of pollution into domestic waters [1]. As a U.S. regulatory entity, the Environmental Protection Agency (EPA) is charged with enforcing the guidelines set forth in this legislation through the National Pollution Discharge Elimination System Permit Program (NPDES). The NPDES Permit Program's Construction General Permit (CGP) affects all construction sites that disturb more than one acre of land [2]. Although the EPA instituted the NPDES permit program and its guidelines, they have passed on the authority to enforce and further regulate these practices to state-level NPDES permit programs [3]. Currently there are forty-seven states with authorized NPDES permitting programs, some of which further delegate this authority to individual municipalities through Municipal Separate Storm Sewer System (MS4) stormwater permitting [4]. State, municipal, and other entities granted this authority via the EPA are required 
Street, P., Holley, P. / Proceedings of the Creative Construction Conference (2019) 085

https://doi.org/10.3311/CCC2019-085

to incorporate or improve upon the federal guidelines through their own, jurisdiction specific, regulations and standards. Authorized state and local entities perform inspections on GCP-regulated construction jobsites to ensure these regulations and standards are enforced.

The majority of regulations and standards found in the federal and state NPDES GCP pertain to erosion and sediment control practices required on construction jobsites [2,3,4]. Also included in this permit, however, is regulation prohibiting the discharge of wastewater produced from the washout of concrete unless managed by an appropriate control $[2,3]$. According to the EPA, this ban is a result of the high alkalinity levels (11-13+), turbity, and metal content found in concrete washout wastewater [5]. The dangerously high alkalinity levels are a product of dissolved limestone used in making concrete [6]. If concrete washout wastewater is not properly contained or treated on a construction site, its contaminants can reach the surface and/or ground water table by the means of storm sewers and direct disposal [5]. While contractors operating on GCP-regulated construction sites must abide by the NPDES regulations to avoid costly fines [4, 11], many contractors report that enforcement entities focus almost entirely on the erosion/sediment control $[7,11]$. Although the regulations have been in effect for decades, only recently have certain entities, primarily at the MS4 level, begun levying fines related to concrete washwater discharge [7,11]. This has led to interest in and concern by contractors, and was the impetus for this research.

The EPA and many of the state and local authorized entities provide contractors with recommended best management practices (BMPs) for use on jobsites in order to handle concrete washout waste [5]. While these BMPs represent a wide range of strategies, most all of them function such that all solid (concrete/aggregate), semi-solid (slurry), and liquid (washwater) waste produced from cleaning equipment that is used for placing and finishing concrete is to be contained and eventually treated either at an offsite facility, or by means of evaporation $[2,5,7]$. The design of these collection containers range from single-use bag-like containers, to more durable containers which are reusable $[2,5,7]$. An additional recommended BMP is the use of a subgrade pit lined with plastic which allows the contaminated wastewater to either be evaporated or removed and transported to a treatment facility off site.

\subsection{Containment of Concrete Washout Waste}

A pilot study conducted in 2018 by Holley, Lynn, Bush and Chavan [7] found that even with the looming threat of fines and pollution, many contractors struggle with the recommended BMPs due to the efficiency, mobility, and safety of containment products currently available (Fig. 1(a.)). This prompted those researchers to analyze the design of current containment products, and develop a new prototype container that was more practical and mobile, enabling it to realistically be implemented on a jobsite (Fig. 1(b.)). After development and testing of prototypes, they concluded that although the development of a new container had promise, the real challenge was in containing the large volume of washwater produced during the washout process [7]. "From a volumetric perspective, the water could easily make up a significant portion of the contaminated components that need to be contained, and perhaps even more difficult to do so" [7].
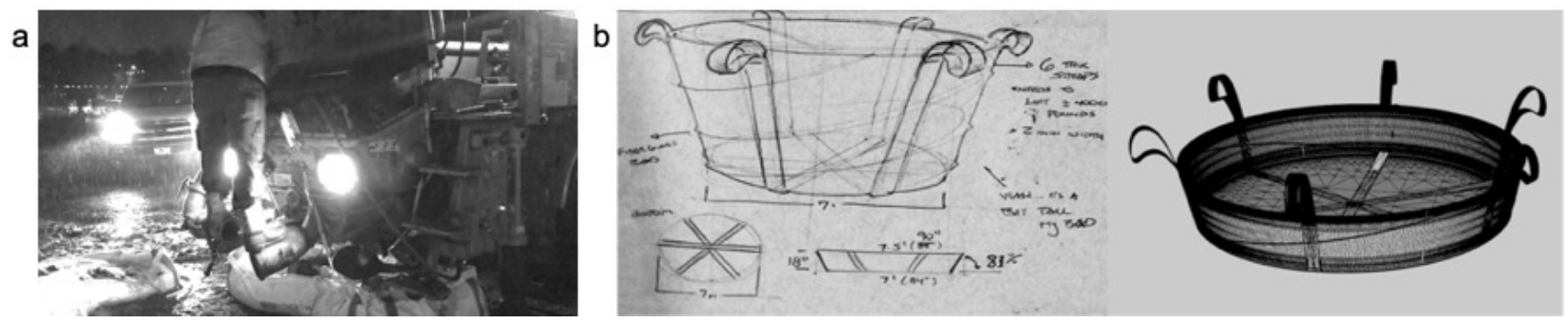

Fig.1. (a.) Vinyl Bag Being Utilized in Unsafe Conditions (b.) Protoype Developed [7]

\subsection{Rationale for the Research: Determining Jobsite Conditions for Potential Neutralization}

Based on the conclusions made by Holley, et al, the authors sought to continue the research by analyzing the contaminates found in the wastewater, to better understand if treating/neutralizing the washwater on the jobsite as part of the clean-up process is feasible. The specific aim of this research is to determine the chemical composition of 
Street, P., Holley, P. / Proceedings of the Creative Construction Conference (2019) 085

https://doi.org/10.3311/CCC2019-085

wastewater produced in the washout process under realistic jobsite conditions, creating a baseline for which future research can use in determining a potential solution.

In order to identify and test potential means of neutralization, standards which concrete washwater should meet in order to be directly discharged on site would need to be identified. A review of relevant literature illuminated an abundance of published research pertaining to recycling concrete wastewater, but most all focused on ready mix plants and industrial concrete production sites, such as the studies by Su, Miao, and Liu, in 2002 [8], and Chini and Mbwambo in 1996 [6]. However, no significant research was found on the responsible disposal of concrete wastewater on construction sites.

This led researchers to have discussions with the EPA and State environmental management authorities in the exploration of collection standards and metrics used for evaluating contaminants found in concrete washout wastewater on a construction site. These discussions yielded there are currently no published collection standards or metrics at the federal level. Based on this, the investigators proposed the use of standards established for collecting and monitoring the discharge of wastewater produced from a permitted temporary concrete batch plant, which regulatory representatives found reasonable [4,9]. Projects requiring a large quantity of concrete have the ability to construct temporary batch plants on the jobsite under this permit, representing similar conditions to washout waste produced from mixers and pump trucks on site. Based on geographic location, the authors chose to utilize standards set at their home state level [10].

\section{Methods}

\subsection{Variables}

Due to the nature of the research, a pilot study approach was used so that future research could be better informed. Two potential options were identified for the collection process; samples could either be collected from a construction site in actual conditions, or from a simulated scenario in a lab. Although collecting or developing samples in a lab environment would provide researchers with control of more variables, the authors decided that sample collection from working construction sites would give this research the advantage of identifying how actual jobsite conditions affect the data collected. That said, realistic site conditions provide a range of variables that could affect the composition of samples. Variables identified for which researchers had reasonable control included the type of equipment being cleaned, compressive strength of concrete (i.e., cement content), amount of water used in the clean-up process, and the size/type of waste container. More difficult to control, but identifiable, were agitation and extraction practices, source of the water used in clean-up, and the presence of admixtures such as plasticizers, calcium, and fly ash.

Discussions with industry professionals suggested that the cleaning of concrete pump trucks produces the largest amount of contaminated washout waste on a typical jobsite, as compared to that produced by a mixing truck's direct chute. During the cleaning process of a pump truck, its hopper contains an average of $1 / 4 \mathrm{CY}$ to $1 / 2 \mathrm{CY}$ of solid waste in the form of uncured concrete. After solid waste is discharged from the hopper, between 40 and 50 gallons of water is typically used to clean the residual concrete from the interior of the hopper and the boom pipe [7, 11].

Samples from three residential concrete pours were collected. The pour identification, compressive strength, admixtures, and water source used for cleaning is displayed in table 1.

Table 1. Pilot Study Pour Makeup

\begin{tabular}{cccc}
\hline Pour ID & $\begin{array}{r}\text { Compressi } \\
\text { ve Strength }\end{array}$ & Admixtures & Water Source \\
\hline$A$ & $3000 \mathrm{psi}$ & $1 \%$ calcium chloride, fly ash & Well \\
$B$ & $3000 \mathrm{psi}$ & N/A & Municipal Utility \\
$C$ & $3000 \mathrm{psi}$ & N/A & Municipal Utility \\
\hline
\end{tabular}


Street, P., Holley, P. / Proceedings of the Creative Construction Conference (2019) 085 https://doi.org/10.3311/CCC2019-085

\subsection{Collection}

For each pour, the pump truck emptied the remaining solid concrete/aggregate left in the hopper into a $16 \mathrm{CF}$ portable washout box (Fig. 2(a)) supplied by the authors. The operator then cleaned the residual concrete remaining in the hopper with a water hose, to which a flow meter was attached and used to quantify the amount of water that was being used to clean the truck. To determine the effects of water quantity and potential dilution, samples were taken at three separate intervals based on the amount of water used to clean the pump truck: 10 gallons, 20 gallons, and 40 gallons (Fig. 2(b)). At each stage, researchers collected sample sets from the portable washout box in triplicate, to identify any abnormal data and to ensure the samples taken were an accurate representation of the chemical composition of the wastewater at that point in the washout process.
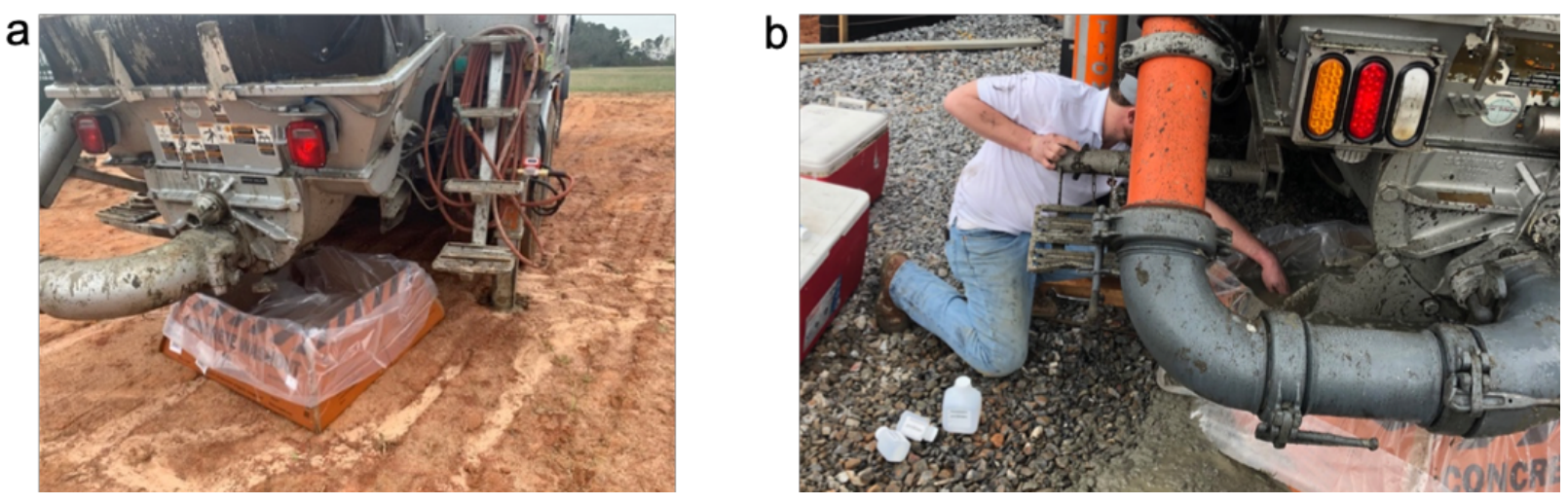

Fig. 2. (a) Portable Washout Box and (b) Sample Collection

\subsection{Analysis Protocol}

Sample sets were labeled based upon their corresponding pour ID, amount of water used as of the time the sample was collected, and the order in which each sample was taken in triplicate. Each sample set consisted of six containers which were also identified in accordance with the contents of each container and the testing requirements (e.g. the container used to test the $\mathrm{pH}$ was plastic, and the container used to test oil and grease was glass), based on EPA-certified lab protocol. To preserve their contents, samples were packed in ice after collection and then delivered directly to the lab, at which point the chain of custody forms were executed to begin analysis.

Testing and analysis of each sample's chemical makeup was performed by an EPA-certified laboratory. The accreditation of this lab was beneficial to this research since they routinely perform these tests and are certified to do so by the governing body that enforces these regulations, at both federal and state level.

\section{Results}

The analysis process underwent rigorous quality control/quality assurance parameters to ensure the sample sets were tested based on state and federal requirements by the NPDES Permit Program. Results were posted to a secure online database where researchers collated data from each individual sample set. Based on the pour mix design, location, and stage in the washout process from which the samples were collected, researchers aggregated the results for each sample set taken in triplicate (Table 2). Triplicates were averaged for analysis based on milestones signified by gallons of water used during the washout process in order identify patterns found across the data. Outlying data observed or suspected was reviewed with lab technicians to confirm results. 
Street, P., Holley, P. / Proceedings of the Creative Construction Conference (2019) 085

https://doi.org/10.3311/CCC2019-085

Table 2. Washwater Analysis Results, per regulatory standards for temporary jobsite batch plants [10]

\begin{tabular}{|c|c|c|c|c|c|}
\hline \multicolumn{6}{|c|}{3000 PSI $\quad \mu$ of Triplicate Samples } \\
\hline \multicolumn{6}{|c|}{ AdMix: $1 \%$ calcium chloride, + fly ash } \\
\hline TEST & (a) 10 gallons used & (a) 20 gallons used & (a) 40 gallons used & Units & Max per Standard [10] \\
\hline $\mathrm{pH}$ & 12.4 & 12.2 & 11.87 & SU & 8.5 \\
\hline Total Phosphorus & 47.00 & 2.78 & 1.43 & $\mathrm{mg} \mathrm{P} / \mathrm{L}$ & 1 \\
\hline TSS & $12,526.67$ & 1630.00 & 810.00 & mg/L (dry) & 50 \\
\hline TRC & 0.65 & 0.87 & $<0.02$ & $\mathrm{mg} / \mathrm{L}$ & 0.019 \\
\hline Chlorides & 520.00 & 1260.00 & 268.00 & $\mathrm{mg} / \mathrm{L}$ & 860 \\
\hline TDS & 3346.67 & 2226.67 & 1009.33 & $\mathrm{mg} / \mathrm{L}$ (dry) & monitor \\
\hline Oil and Grease & 27.33 & 19.33 & 23.33 & $\mathrm{mg} / \mathrm{L}$ & 15 \\
\hline
\end{tabular}

POUR 'B' February 27, 2019 College Park, GA AdMix: None

\begin{tabular}{lccccc}
\hline TEST & @ 10 gallons used & @ 20 gallons used & @ 40 gallons used & Units & Max per Standard [10] \\
\hline $\mathrm{pH}$ & 12.43 & 12.13 & 12.00 & $\mathrm{SU}$ & 8.5 \\
Total Phosphorus & 1.30 & 0.51 & 0.45 & $\mathrm{mg} \mathrm{P} / \mathrm{L}$ & 1 \\
TSS & 3030.00 & 1630.00 & 810.00 & $\mathrm{mg} / \mathrm{L}(\mathrm{dry})$ & 50 \\
TRC & 0.21 & 1.07 & 0.45 & $\mathrm{mg} / \mathrm{L}$ & 0.019 \\
Chlorides & 401.67 & 355.00 & 605.00 & $\mathrm{mg} / \mathrm{L}$ & 860 \\
TDS & 3543.33 & 2610.00 & 20.00 & $\mathrm{mg} / \mathrm{L}(\mathrm{dry})$ & $\mathrm{monitor}$ \\
Oil and Grease & 26.00 & 24.67 & & & 15
\end{tabular}

\begin{tabular}{lccccc}
\hline & POUR 'C' & March 1, 2019 & Fairburn, GA & AdMix: None \\
\hline TEST & @ 10 gallons used & @ 20 gallons used & @ 4 40 gallons used & Units & Max per Standard [10] \\
\hline pH & 12.67 & 12.63 & 12.30 & SU & 8.5 \\
Total Phosphorus & 8.35 & 5.87 & 1.64 & $\mathrm{mg} \mathrm{P} / \mathrm{L}$ & 1 \\
TSS & $94,933.33$ & $36,663.33$ & 8050.00 & $\mathrm{mg} / \mathrm{L}$ (dry) & 50 \\
TRC & 2.19 & 2.19 & 0.90 & $\mathrm{mg} / \mathrm{L}$ & 0.019 \\
Chlorides & 405.00 & 515.00 & 555.00 & $\mathrm{mg} / \mathrm{L}$ & 860 \\
TDS & 4593.33 & 4190.00 & 2470.00 & $\mathrm{mg} / \mathrm{L}$ (dry) & monitor \\
Oil and Grease & 22.67 & 12.00 & 16.67 & $\mathrm{mg} / \mathrm{L}$ & 15
\end{tabular}

\section{Conclusions and Recommendations}

\subsection{Conclusions}

Data show multiple items and patterns that may be important in next steps of the research. First, that the use of more water in the cleaning process did not significantly reduce the alkalinity of the waste/washwater. Researchers believe this may be the result of water being used in the cleanout process further agitating the solid (concrete/aggregate) and semi-solid (slurry) waste in the container, causing cement in the solid and semi-solid waste to separate and further 
Street, P., Holley, P. / Proceedings of the Creative Construction Conference (2019) 085 https://doi.org/10.3311/CCC2019-085

disperse in the liquid waste, continuing to contaminate the wastewater. Second, that total suspended solids (TSS) diminished substantially over the course of the clean-up process. As this is a major contaminant according to the EPA [7], data suggest that perhaps a filtration strategy could have potential. Next, some contaminants actually increased while using more water in the process, most notably the chlorides. However, data suggest that this is more prevalent when treated municipally sourced water is used, as opposed to well water. And finally, some contaminants such as total phosphorus and oil/grease are shown to be at or relatively near acceptable levels for discharge, leaving continued research to prioritize the contaminants to be neutralized.

\subsection{Limitations}

Researchers acknowledge that this pilot study has certain limitations. Foremost, samples collected in a quantitative sample size may more accurately represent jobsite conditions of contaminants than data from this study. While collecting samples in the field gave the authors the advantage of collecting data from realistic construction jobsite conditions, limitations on not being able to control certain variables such as the amount of solid waste remaining in the hopper or the origin of the water used to clean may have also impacted the results. Data from Pour C suggest an unusually high level of TSS, supporting this concern. From an analysis perspective, the EPA-certified lab notified researchers that due to the nature of the matrix being tested in the samples, results for Total Residual Chloride (TRC) could be inaccurate. Suspended solids found in the samples can cause the spectrometer used to test TRC to display inaccurate results. Future research may need to seek an alternative method to test for TRC.

\subsection{Future Research}

As this pilot study targeted the collection of concrete washout wastewater under realistic jobsite conditions, multiple opportunities can be identified for future research. A new study could include results taken from a larger quantitative sample size to more accurately represent the characteristics of wastewater samples collected during the washout process. This study could be expanded to include results from waste created by concrete having different mix designs, such as having 4000psi compressive strength, the addition of plasticizers, etc. Samples could also be collected from a simulated concrete washout scenario in a laboratory, giving researchers better control of the variables found on a construction site. The results found in this pilot study also facilitate a need to revisit the design of the concrete washout containers. Based on the results found in this study, early discussions with regulatory agencies suggest that a priority of future research should address the level of contaminants identified in the $\mathrm{pH}$ and Total Suspended Solids (TSS) results $[4,9]$. Future designs could potentially investigate fabrics, polymers or nanotechnologies such as naturally occurring tree cellulose to potentially neutralize water created during the washout process such that it could be discharged on site.

\section{References}

[1] United States, Federal Water Pollution Control Act Amendments of 1972, 1972.

[2] United States Environmental Protection Agency, National Pollution Discharge Elimination System General Permit for Discharges From Construction Activities, 2017.

[3] Alabama Department of Environmental Management, National Pollution Discharge Elimination System Permit General Permit: Discharges From Construction Activities, 2016.

[4] J. Pritts, Office of Science and Technology, U.S. Environmental Protection Agency, Personal Interview by phone, February $5^{\text {th }}, 2019$.

[5] United States Environmental Protection Agency Office of Water, Stormwater Best Management Practice: Concrete Washout, https://www3.epa.gov/npdes/pubs/concretewashout.pdf, retreived January $15^{\text {th }}, 2019$.

[6] A.S. Chini, W.J. Mbwambo, Environmentally Friendly Solutions for the Disposal of Concrete Wash Water from Ready Mixed Concrete Operations, Proceedings of CIB W89 Beijing International Conference, 1996.

[7] P.W. Holley, E.P. Lynn, Bush, Chavan, An Interdisciplinary Pilot Study and Prototype Development for the Containment of Concrete Washout Waste, Proceedings of the Associated Schools of Construction, Denver, CO, 2019.

[8] N. Su, B. Miao, F.S. Liu, Effect of wash water and underground water on properties of concrete. Cement and Concrete Research (2002) 32, 777782.

[9] H. Griffin, Permits and Services Div., Alabama Department of Environmental Management, Personal Interview by Phone, February $21^{\text {st }}, 2019$.

[10] Alabama Department of Environmental Management, National Pollution Discharge Elemination System General Permit: Discharges From Concrete Batch Plants, http://adem.alabama.gov/programs/water/permits/ALG1 10000Concrete.pdf, p6, retrieved February $8^{\text {th }}, 2019$.

[11] W. Bylsma, Business Owner, Interviews in person and by phone, multiple dates in January and February of 2019. 